\title{
p53 promotes VEGF expression and angiogenesis in the absence of an intact p21-Rb pathway
}

\author{
M Farhang Ghahremani ${ }^{1,2}$, S Goossens ${ }^{1,2}$, D Nittner ${ }^{3,4}, X_{\text {Bisteau }}^{5}$, S Bartunkova ${ }^{1,2}$, A Zwolinska ${ }^{3,4}$, P Hulpiau $^{1,2}, K_{\text {Haigh }}{ }^{1,2}$, \\ L Haenebalcke ${ }^{1,2}$, B Drogat ${ }^{1,2,7}$, A Jochemsen ${ }^{6}$, PP Roger ${ }^{5}$, J-C Marine ${ }^{3,4,8}$ and JJ Haigh ${ }^{\star, 1,2,8}$
}

There is growing evidence that the p53 tumour suppressor downregulates vascular endothelial growth factor (VEGF) expression, although the underlying mechanisms remain unclear and controversial. Here we provide insights from in vitro experiments and in vivo xenotransplantation assays that highlight a dual role for p53 in regulating VEGF during hypoxia. Unexpectedly, and for the first time, we demonstrate that p53 rapidly induces VEGF transcription upon hypoxia exposure by binding, in an HIF-1 $\alpha$ dependent manner, to a highly conserved and functional p53-binding site within the VEGF promoter. However, during sustained hypoxia, p53 indirectly downregulates VEGF expression via the retinoblastoma $(\mathbf{R b})$ pathway in a p21-dependent manner, which is distinct from its role in cell-cycle regulation. Our findings have important implications for cancer therapy, especially for tumours that harbour wild-type TP53 and a dysfunctional Rb pathway.

Cell Death and Differentiation (2013) 20, 888-897; doi:10.1038/cdd.2013.12; published online 1 March 2013

Vascular endothelial growth factor (VEGF) is an essential modulator of angiogenesis during both physiological and pathological hypoxia. It stimulates endothelial cell survival, mitogenesis and cell migration in vitro, and is essential for the generation of new blood vessels during embryonic development and in the adult after injury. ${ }^{1}$ Furthermore, high VEGF levels correlate with decreased overall and disease-free survival in various solid cancers. ${ }^{2,3}$ During tumour growth, VEGF levels increase owing to cellular stress, such as hypoxia, and changes in the tumour microenvironment. VEGF has multiple roles during various steps of tumour progression by stimulating vessel growth to provide the necessary oxygen and nutrients, ${ }^{4}$ but alterations in VEGF signalling have been suggested to have key roles in driving metastasis ${ }^{5,6}$ and modulating cancer stemness through both autocrine and paracrine mechanisms. $^{7}$

p53 is a central component of most cellular stress responses, including hypoxic stress. ${ }^{8}$ Upon activation, p53 can positively or negatively regulate the expression of numerous target genes involved in various essential cellular processes, including cell proliferation, survival and angiogenesis. ${ }^{9}$

Despite putative cross-talk mechanisms between p53 and VEGF, how these two key cancer-signalling pathways functionally interact remains unclear. While Agani and coworkers reported $^{10}$ that VEGF mRNA levels remain unchanged following activation of endogenous or exogenous p53 in Hep3B human hepatoblastoma or in RKO human colorectal carcinoma cell lines, others have shown that wildtype (WT) p53 can repress VEGF transcription in vitro. ${ }^{11}$ p53 has been shown to repress VEGF transcription by direct binding and sequestration-positive transcriptional regulator SP1 and/or binding to the E2F transcription factor forming a transcriptional repressor complex for VEGF expression. ${ }^{12-14}$

Mdm2 and HIF-1 $\alpha$, key modulators of the p53 and VEGF pathways, respectively, further complicate the situation. Under hypoxic conditions, $\mathrm{HIF}-1 \alpha$ protein is stabilized allowing direct binding to and activation of the VEGF promoter. ${ }^{15}$ Although evidence exists that during hypoxia HIF-1 $\alpha$ can directly interact with and stabilize WT p53 protein, ${ }^{16}$ others have shown that HIF- $1 \alpha$ does not directly interact with $\mathrm{p} 53$ and the HIF-1 $\alpha-$ p53 interaction occurs only in the presence of Mdm2. Mdm2-dependent p53-HIF-1 $\alpha$ interaction decreases Mdm2-mediated degradation and nuclear export of p53. ${ }^{17} \mathrm{At}$ the same time, p53 promotes Mdm2-mediated ubiquitylation and proteasomal degradation of HIF-1 $\alpha .{ }^{18}$ This is in contradiction with the role of $\mathrm{Mdm} 2$ as an $\mathrm{HIF}-1 \alpha$ activator during hypoxia in tumour cells. ${ }^{19}$

To understand this cross-talk between p53 and VEGF regulation under hypoxic conditions further, we have performed in vitro experiments using non-transformed primary mouse embryonic fibroblasts (MEFs) and in vivo xenotransplantation assays. We observed that p53 has contrasting roles in the regulation of VEGF expression during hypoxia. Unexpectedly, we find that p53 cooperates with HIF-1 $\alpha$ to positively regulate VEGF expression during initial acute

${ }^{1}$ Vascular Cell Biology Unit, Department for Molecular Biomedical Research, VIB, Ghent, Belgium; ${ }^{2}$ Department for Biomedical Molecular Biology, Ghent University, Ghent, Belgium; ${ }^{3}$ Center for the Biology of Disease, VIB-KU Leuven, Leuven, Belgium; ${ }^{4}$ Laboratory for Molecular Cancer Biology, Center for Human Genetics, Faculty of Medicine, KU Leuven, Leuven, Belgium; ${ }^{5}$ Interdisciplinary Research Institute en Biologie Humaine et Moleculaire, Université Libre de Bruxelles, Campus Erasme, Brussels, Belgium and ${ }^{6}$ Leiden University Medical Centre, Department of Molecular Cell Biology, Leiden, The Netherlands

*Corresponding author: J Haigh, Department for Biomedical Molecular Biology, Ghent University, Technologiepark 927, Ghent (Zwijnaarde), 9052 Belgium. Tel: + 3293313 661; Fax: + 3293313 609; E-mail: Jody.haigh@dmbr.vib-UGent.be

${ }^{7}$ Current address: Interdisciplinary Research Institute en Biologie Humaine et Moleculaire, Université Libre de Bruxelles, Brussels, Belgium

${ }^{8}$ These authors contributed equally to this work.

Keywords: VEGF; p53; angiogenesis; p21

Abbreviations: bp, base pair; $\mathrm{E}$, embryonic day $n$; KD, knockdown; KO, knockout; Rb, retinoblastoma; sh, short hairpin; VEGF, vascular endothelial growth factor Received 16.7.12; revised 02.1.13; accepted 21.1.13; Edited by M Oren; published online 01.3.13 
hypoxic conditions. However, after prolonged exposure to hypoxia or when cells are exposed to genotoxic stress, p53 represses VEGF expression in a p21/retinoblastoma $(\mathrm{Rb})$ dependent manner. Accordingly, activation of p53 in cells deficient for $\mathrm{p} 21 / \mathrm{Rb}$ pathway leads to a sustained increase in VEGF expression and promotes angiogenesis in xenograft models of retinoblastoma. As the $\mathrm{p} 21 / \mathrm{Rb}$ tumour suppressor pathway is defective in a high proportion of solid tumours, including retinoblastoma, these findings indicate that chemical reactivation of $p 53$ in such tumours should be undertaken with caution owing to the positive transcriptional effects of p53 on VEGF expression under hypoxia conditions in these tumours.

\section{Results}

p53 induces VEGF transcription during the initial stages of hypoxia. Interpretation of the putative cross-talk between p53 and VEGF signalling has so far been complicated owing to the use of cancer cell lines that have accumulated many uncharacterized oncogenic lesions due to genomic instability. Here we have revisited the role of p53 in VEGF transcriptional regulation in non-transformed cells. To this end, we exposed various genetically engineered primary MEFs to hypoxia $\left(0.5 \% \mathrm{O}_{2}\right)$. We monitored VEGF expression by quantitative reverse transcription-polymerase chain reaction (qRT-PCR) at an early $(4 \mathrm{~h})$ and a late $(24 \mathrm{~h})$ time point during hypoxia exposure. VEGF expression levels showed a threefold increase at $4 \mathrm{~h}$ and a significant decrease at $24 \mathrm{~h}$ (Figure 1a and Supplementary Figure 1A). The hypoxiaregulated PFK promoter, which contain HIF-1 $\alpha$-binding sites, served as the control for hypoxia induction (data not shown). ${ }^{20}$

Unexpectedly, at the early time point, hypoxia-dependent VEGF induction was significantly attenuated in p53-null MEFs, indicating that p53 contributes to this upregulation (Figure 1a). Hypoxia and DNA damage induce p53 via distinct mechanisms and activate different p53 transcriptional programmes and biological responses. To test whether DNA damage-induced p53 stabilization promotes induction of VEGF, we induced p53 using doxorubicin $(0.4 \mu \mathrm{g} / \mathrm{ml})^{21}$ in normoxic and hypoxic conditions. We found that doxorubicininduced p53 stabilization is not sufficient to promote VEGF induction in normoxic conditions; it even decreased the hypoxic-dependent induction of VEGF mRNA levels (Figure 1b). In contrast to DNA damage, hypoxia alone does not stabilize p53 as reported previously, ${ }^{22}$ and only showed increased and stabilized expression when the cells were treated with doxorubicin as well (Figure 1c). These data indicate that $\mathrm{p} 53$ has a positive role in the initial induction of VEGF in response to hypoxia, but not in response to DNA damage alone. Moreover, DNA damage interferes with the ability of p53 to induce VEGF expression in hypoxic conditions in WT MEFs. Importantly, p53 also contributes to the downregulation of VEGF expression at the late time point. This is consistent with previous reports that p53 can directly repress the VEGF promoter. ${ }^{11}$

To further validate the positive effects of p53 on VEGF expression, we used MEFs harbouring a lox-stop-lox (LSL) transcription cassette inserted into the first intron of p53 and also lacks the p53-negative regulator Mdm2 (Mdm2 - / p53 LSL/ - hereafter referred to as $2 \mathrm{KO}$ (knockout) cells). Consistent with a previous study, ${ }^{23}$ Cre-mediated excision of the LSL cassette leads to an accumulation of p53 in the absence of exogenous DNA damage (Figure 1d). Following exposure to hypoxia, reactivation of p53 (Mdm2 - / - , p53 + / - , hereafter referred to as $2 \mathrm{KO}+\mathrm{C}$ ) caused a robust increase in VEGF levels after $4 \mathrm{~h}$ (Figure 1e). This genetic rescue experiment confirms that p53 promotes the initial induction of VEGF expression during hypoxia (Figure 1b). VEGF mRNA levels were further increased at $24 \mathrm{~h}$, indicating a negative role of Mdm2 in the modulation of VEGF expression under conditions of extended hypoxia (Figure 1e). Consistent with the mRNA expression data, $2 \mathrm{KO}+\mathrm{C}$ cells show higher protein levels compared with $2 \mathrm{KO}$ cells (Figure 1f). Therefore, we conclude that p53 is able to induce VEGF during the initial phases of hypoxia and our data are consistent with previous reports of the negative role of Mdm2 on HIF- $1 \alpha$ function. ${ }^{18}$

p53 binds to VEGF promoter synergistically with HIF-1 $\alpha$ to induce VEGF expression during early hypoxia. To determine whether p53 directly binds to the VEGF promoter and leads to increased VEGF mRNA expression during early hypoxia, we performed an in silico promoter analysis of the VEGF promoter using the ConTra algorithm. ${ }^{24}$ We identified three highly conserved putative p53-binding sites. Region 1 (R1) contains a conserved double p53-binding site, one part being directly adjacent to the well-characterized, highly conserved and functional HIF- $1 \alpha$-binding site, ${ }^{25}$ while the other p53-binding site lies 64 base pair (bp) upstream. Region 2 (R2) is located in the first intron where the p53 and $\mathrm{HIF}-1 \alpha$ sites overlap and region $3(\mathrm{R} 3)$ is another double p53 site with a $9 \mathrm{bp}$ spacer and is also located in the first intron (Figure 2a and Supplementary Figure 2).

To investigate the functionality of these putative p53binding sites, we performed chromatin immunoprecipitation (ChIP) experiments. Primers were designed to flank the putative p53-binding sites R1, R2 and R3. In WT cells, p53 binds to R1, but not R2 or R3, after $4 \mathrm{~h}$ of exposure to hypoxia. p53 recruitment to $\mathrm{R} 1$ was observed in the $2 \mathrm{KO}+\mathrm{C}$ cells but not in HIF-1 $\alpha$ null cells, indicating that while the presence of $\mathrm{HIF}-1 \alpha$ is required for p53 binding, Mdm2 protein is not necessary for the binding of p53 to the VEGF promoter at R1 region $^{19}$ (Figure $2 b$ ). To further confirm that this $\mathrm{R} 1$ site is required for hypoxia-dependent VEGF induction, we transfected VEGF promoter luciferase constructs, which contains 1.6-kb fragment of VEGF genomic DNA, encompassing $1.2 \mathrm{~kb}$ of the $5^{\prime}$-flanking sequence of the transcription start site and $0.4 \mathrm{~kb}$ of corresponding $5-\mathrm{UTR}^{26}$ into WT, p53-null and HIF- $1 \alpha$-null MEFs, and exposed these cells to hypoxia for $4 \mathrm{~h}$. While hypoxia induced luciferase activity in WT cells, it did not in p53- or HIF-null MEF cells (Figure 2c). Mutation of either the $\mathrm{p} 53$ or HIF-1 $\alpha$ putative binding sites in R1 (referred to $\Delta \mathrm{p} 53$ and $\Delta \mathrm{HIF}-1 \alpha$, respectively) in the VEGF promoter abrogated the hypoxia-induced luciferase activity (Figure 2c). These results indicate that hypoxia-induced VEGF expression requires the co-recruitment of both $\mathrm{HIF}-1 \alpha$ and p53 to the $\mathrm{R} 1$ site during the initial stages of hypoxia. 


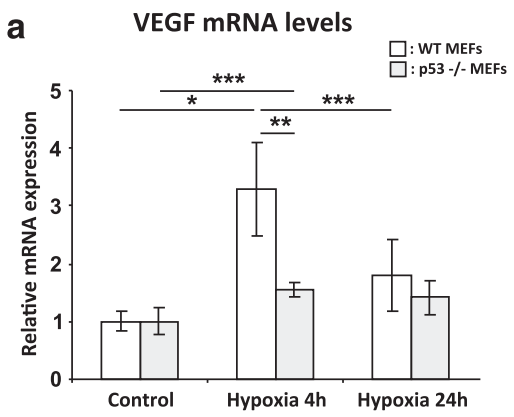

C b

WT MEFs - VEGF mRNA levels

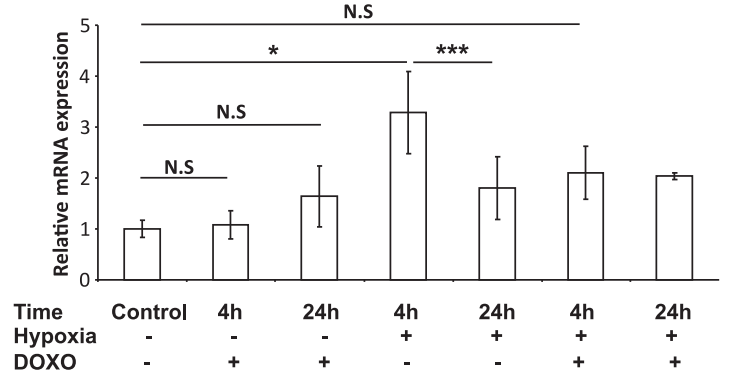

d WT \& 2KO+C MEFs - p53 levels
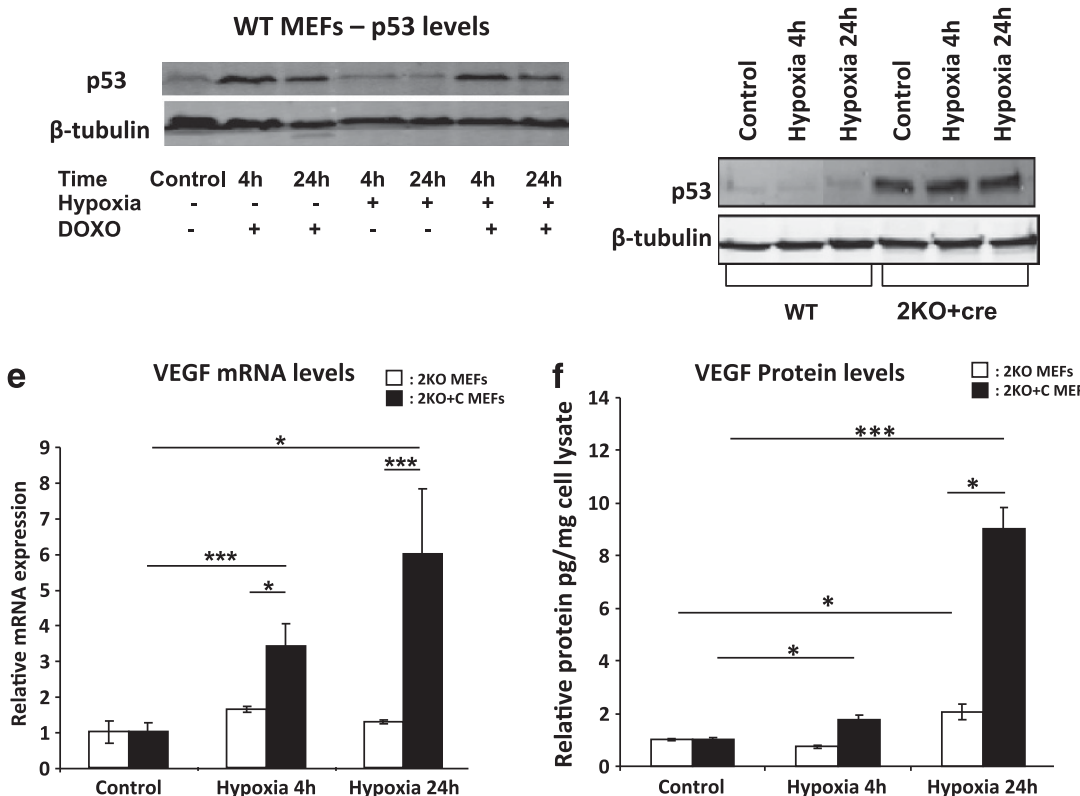

Figure 1 p53 induces VEGF transcription during the initial stages of hypoxia. (a and $\mathbf{b}$ ) Relative VEGF mRNA levels measured by qRT-PCR ( $n=3$ ). (a) WT MEF cells displaying a 3.2-fold induction of VEGF mRNA after $4 \mathrm{~h}$ hypoxia. p53 - I - MEFs display significantly less induction of VEGF mRNA upon hypoxia. (b) VEGF mRNA levels in WT MEFs do not change by stabilizing p53 with doxorubicin in normoxic $\left(20 \% \mathrm{O}_{2}\right)$ conditions. However, the hypoxic induction is decreased upon activation of p53 via doxorubicin. (c) Western blot showing increased expression of p53 only upon doxorubicin treatment and not with hypoxia alone. (d) Western blot displaying p53 levels after Cre excision in Mdm2 - / - , p53 LSL/ - MEFs. (e) Relative VEGF mRNA levels were measured by qRT-PCR. There is a significant increase in expression after Cre excision and re-induction of $\mathrm{p} 53(2 \mathrm{KO}+\mathrm{C})(n=4$ for both $2 \mathrm{KO}$ and $2 \mathrm{KO}+\mathrm{C}$ cells) that is further increased in the absence of Mdm2. (f) Relative picogram VEGF protein measured by enzyme-linked immunosorbent assay (ELISA) and normalized against a microgram of cell lysate. Cells display higher levels of protein after re-activation of p53 in the absence of Mdm2. Bars represent mean \pm S.E.M.; NS, nonsignficant; ${ }^{*} P \leqslant 0.05,{ }^{* \star} P \leqslant 0.01$ and ${ }^{* \star \star} P \leqslant 0.005$

p21 is involved in repressing VEGF levels during continued hypoxia. In addition to its positive role in hypoxia-induced VEGF expression at early time points, p53 also functions as a negative regulator of VEGF at later time points. p53-mediated transcriptional repression can either be direct or indirect via induction of microRNAs ${ }^{26}$ or induction of the CDK inhibitor p21 whose activity affects E2F levels, ${ }^{27}$ or by directly binding with E2F, which in turn has been implicated in the transcriptional repression of VEGF. ${ }^{13}$ To investigate the involvement of p21 in VEGF transcriptional repression, p21-null MEFs were subjected to the same hypoxic conditions as described above. As expected, a significant increase in VEGF levels was observed at $4 \mathrm{~h}$ and, importantly and in contrast to WT and p53-null MEFs, this induction was sustained at $24 \mathrm{~h}$ (Figure 3a). Moreover, DNA damage-induced p53 failed to repress VEGF expression in the absence of p21 (Figure 3b). p21-null cells also showed higher VEGF protein levels under hypoxic conditions with and without doxorubicin (Figures $3 c$ and d). In addition, the kinetics and extent of hypoxia-induced VEGF expression in MEFs with a dysfunctional Rb pathway (Rb/p107-null, two key negative regulators of E2Fs activity) was comparable to those seen in p21-null MEFs (Figure 3e).

Despite the fact that p21-deficient cells showed a lack of VEGF repression at the later time points of hypoxia, the overall p21 mRNA and protein levels were not changed under hypoxic conditions alone but only upon doxorubicin- or Nutlininduced stabilization of p53 (Figure $3 f$ and Supplementary 
a

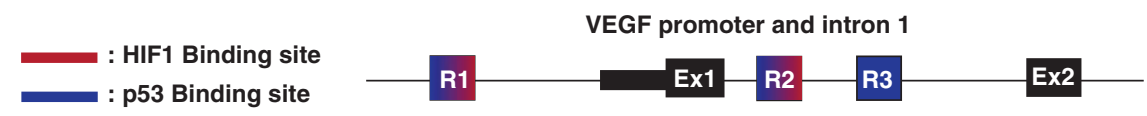

R1: 950 bp upstream promoter region adjacent HIF1 and p53 binding site

GGAACAAGGGC CтстGTCTGCсCAGстGTстстсстTCAGGGстстGCCAGACTACACAGTGCATACGTGGGTTT
CCACAGGTCGTCTCAC

R2: Intron 1 overlapping HIF1 and p53 binding site

ссстCTGTCGTCGTACGTGGAGGGGGAGGGGGTGCGCGCTAGGTGGGAGGGCGCCAGGATCGTCTCGCCGCCCACGCGGG CCCTGCCCACCCACCAGAGTCACCGCACGTACGAT

\begin{abstract}
R3: Intron 1 p53 double binding site
CCTTTGGCAGGATCCCTTGTCAGTCAGTATCTCTCACACACTTTGTCCTGGCAAAGCCCGATGCCCAGAGAGCAGGTGGTT TAACTGCGAACTTGCCCA
\end{abstract}

b

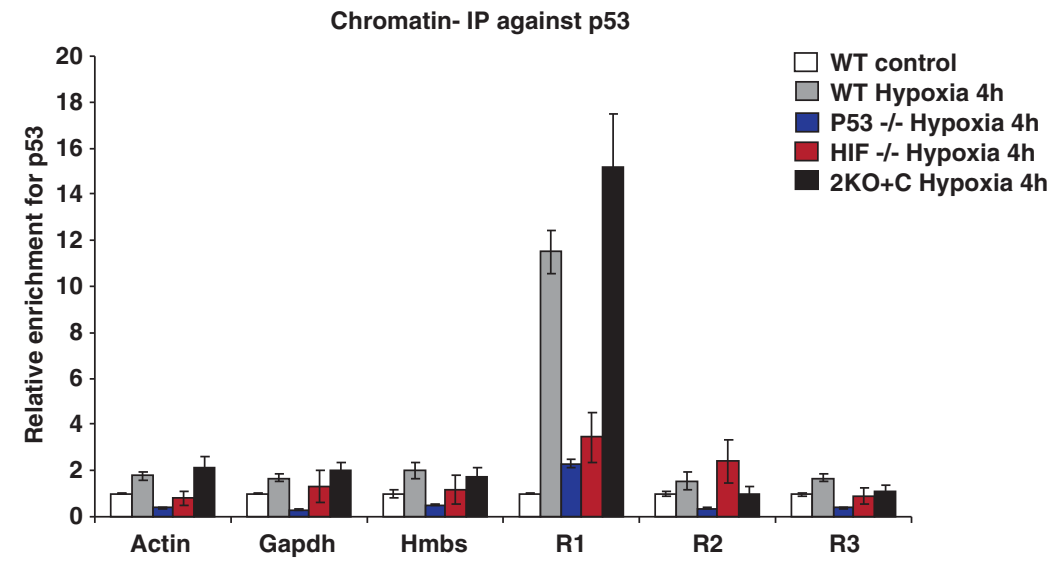

C

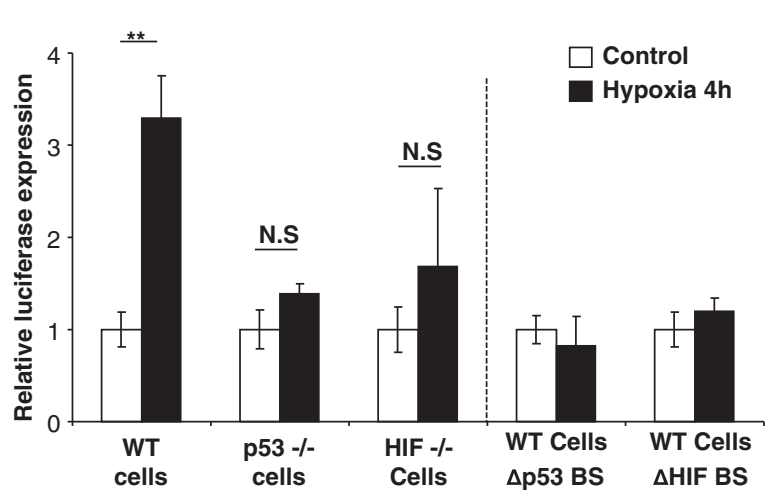

Figure 2 p53 directly binds to VEGF promoter during early hypoxia and is dependent on the presence of HIF- $1 \alpha$. (a) Schematic view of the conserved p53 and HIF- $1 \alpha$ regions analysed by chromatin IP. HIF-1 $\alpha$ (red), p53 (blue) in R1, R2 and R3. (b) Chromatin IP on VEGF promoter using p53 antibody (Ab) in MEFs with different genetic backgrounds after $4 \mathrm{~h}$ of hypoxia. $\mathrm{p} 53$ binds to VEGF promoter in WT and $2 \mathrm{KO}+\mathrm{C}$ MEF cells but fails to bind in HIF- $1 \alpha-/-$, and p53 - I - MEF cells. (c) VEGF promoter luciferase assay $(n=3)$. Luciferase expression only in WT cells that contain complete promoter sequence. Bars represent mean \pm S.E.M.; NS, nonsignificant; ** $P \leqslant 0.01$

Figures $1 \mathrm{~A}$ and $3 \mathrm{~A}, \mathrm{~B})$. Moreover, only in $2 \mathrm{KO}+\mathrm{C}$ cells, where the overall steady-state levels of p53 are increased, does prolonged hypoxia for $24 \mathrm{~h}$ result in increased p21 mRNA levels (Supplementary Figure 3C). Use of the Mdm2 inhibitor Nutlin-3 did not affect the kinetics of VEGF mRNA induction during the initial $4 \mathrm{~h}$ of hypoxia observed in WT, p53-null or p21-null MEFs (Supplementary Figure 1A). However, $24 \mathrm{~h}$ of hypoxia combined with Nutlin-3 treatment in WT cells led to a marginal decrease in VEGF expression, whereas p21-null cells remained unaffected. VEGF protein levels continued to accumulate during the $24 \mathrm{~h}$ period of hypoxia and were highest in all conditions in p21-null cells (Supplementary Figure 1B).

Surprisingly, the levels of E2F protein, known to have a role together with $\mathrm{p} 53$, in the transcriptional repression of VEGF, ${ }^{13}$ showed bi-phasic protein expression levels, whereby during initial hypoxia E2F levels were decreased but were increased during extended hypoxia (Figure $3 f$ ). This was irrespective of p53 stabilization by doxorubicin (Figure 3f). However, the increased E2F protein expression at $24 \mathrm{~h}$ of hypoxia was less 


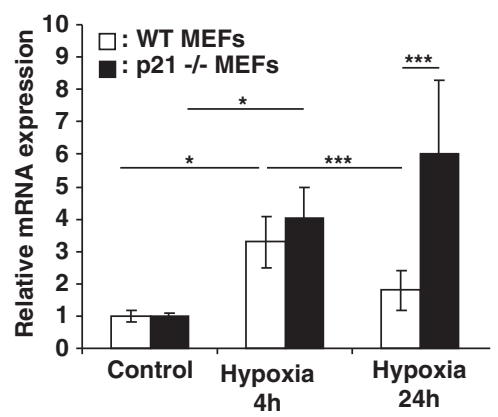

C

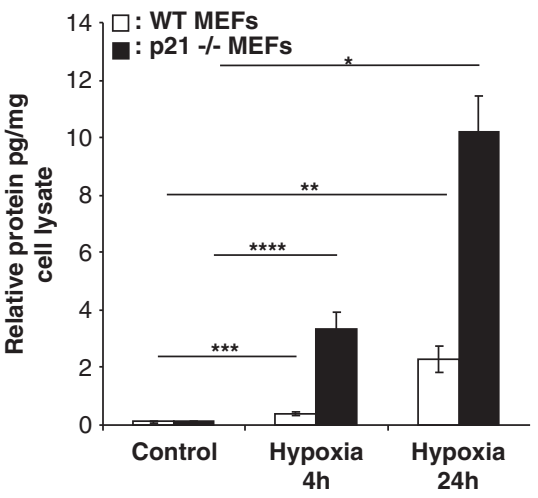

$\mathbf{e}$

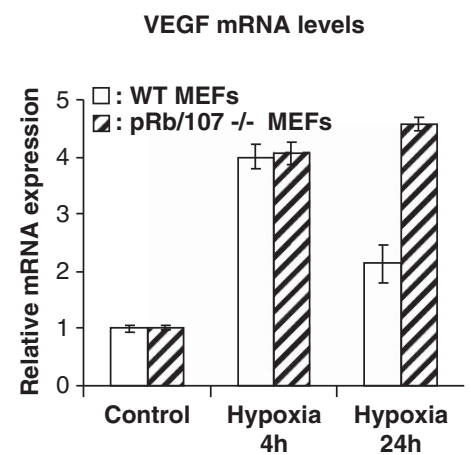

b

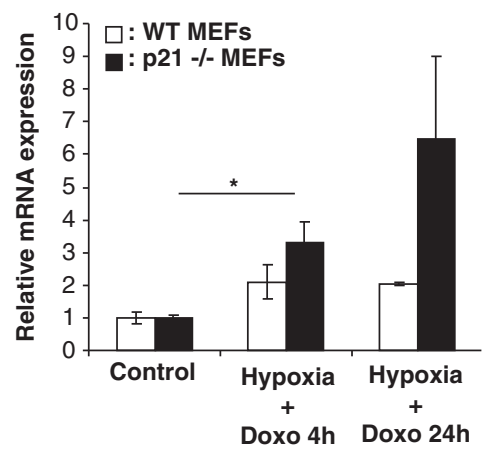

d

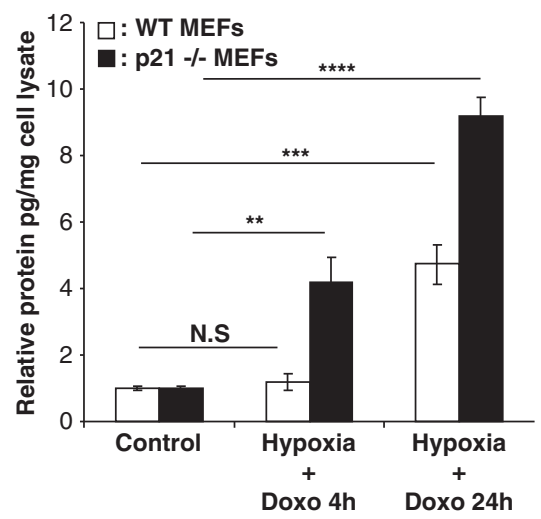

f

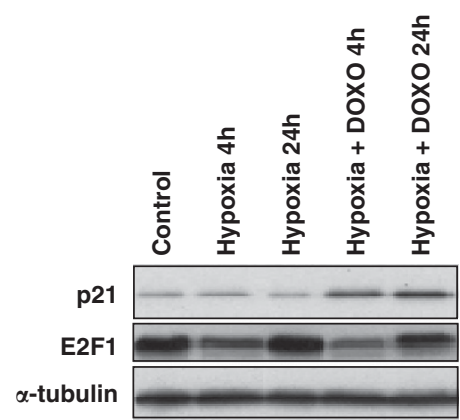

Figure 3 p21 is required for the repression of VEGF expression during extended hypoxia. (a and $\mathbf{b}$ ) Relative VEGF mRNA levels measured by qRT-PCR ( $n=3$ ). (a) VEGF mRNA is induced in p21 - / - MEFs and this induction is stable after $24 \mathrm{~h}$ hypoxia. (b) VEGF expression is induced even upon activation of p53. (c and d) Relative picogram VEGF protein measured by enzyme-linked immunosorbent assay (ELISA) and normalized against a microgram of cell lysate $(n=3)$. P21 $-/$ - MEFs display the highest levels of VEGF protein after hypoxia and stabilization of p53 by doxorubicin. (e) Relative VEGF mRNA levels measured by qRT-PCR. VEGF expression is not repressed in pRb/107 - I - MEFs after $24 \mathrm{~h}$ of hypoxia, displaying a similar trend as p21 - I - MEFs. (f) Western blot on WT cells displaying levels of p21 and E2F during hypoxia and hypoxia combined with doxorubicin. Bars represent mean \pm S.E.M.; NS, nonsignificant; ${ }^{*} P \leqslant 0.05,{ }^{\star \star} P \leqslant 0.01,{ }^{* \star *} P \leq 0.005,{ }^{{ }^{* * \star *}} P \leq 0.001$

pronounced upon continued Nutlin treatment (Supplementary Figure 3B). Here hypoxia alone did not change the phosphorylation status of $R b$, whereas hypophosphorylated (active) $R b$ was greatly increased upon doxorubicin- or Nutlin-3-induced stabilization of $\mathrm{p} 53$ and activation of p21, leading ultimately to decreased Ser10 histone H3 phosphorylation (Supplementary Figure $3 \mathrm{~B}$ ) that has been linked to cell-cycle arrest. 28,29

To confirm p21 involvement in VEGF mRNA repression during extended hypoxia, rescue experiments in p21-null
MEFs were performed by using viral transduction of an HAtagged human p21 construct (Supplementary Figure 3D). We could show that the repressive activity on VEGF mRNA expression in these cells after $24 \mathrm{~h}$ of hypoxia was restored (Supplementary Figure 3E).

p21-null MEFs enhance vascularization in xenotransplanted tumours. There is accumulating evidence that tumour-associated fibroblasts have important roles in tumour growth by releasing key angiogenic cytokines/growth 
factors. ${ }^{30,31}$ To further assess the suppressive role of $\mathrm{p} 21$ on VEGF regulation and its potential implications on tumour angiogenesis, we investigated whether p21-deficient MEFs could enhance tumour angiogenesis compared with WT MEFs, using xenotransplantation experiments. Here HCT116 tumour cells ${ }^{32}$ WT for p53 were combined with p21-null or WT MEFs in a 3:4 ratio and injected subcutaneously in athymic nude (NMRI nu/nu) mice. Tumours injected with p21-null MEFs displayed more vessels than their WT counterparts and displayed fewer hypoxic regions at the tumour periphery (Figures $4 a$ and $b$ and Supplementary Figures 4A and B). In HCT116 tumours derived with WT MEFs, the vasculature was confined to the periphery with tumours displaying large central necrotic areas (Figure $4 \mathrm{a}$ and Supplementary Figure 4A). HCT116 tumours derived with p21-null MEFs had increased vessels surrounding the tissue periphery and at the centre of the tumour, resulting in fewer necrotic regions (Figure 4b). Quantification of vessel density showed that the HCT116 tumours derived with p21deficient MEFs had a $50 \%$ increase in vessel density compared with HCT116-derived tumours that were coinjected with WT MEFs (Figure 4c; $P=0.03$ ). This result was correlated with an approximate twofold increase in
VEGF levels (Figure 4d; $P=0.07$ ). This observation indicates that p21-null MEFs have a positive effect on tumour angiogenesis through enhanced expression of VEGF.

WT p53 promotes angiogenesis in retinoblastoma xenografts. The observation that $\mathrm{p} 53$, in addition to its indirect repressive role in dampening VEGF expression via the $\mathrm{p} 21 / \mathrm{Rb}$ pathway, actually promotes the initial induction of VEGF has significant implications for tumourigenesis. In tumours with a dysfunctional $\mathrm{p} 21 / \mathrm{Rb}$ pathway, p53 activation may promote VEGF expression via HIF- $1 \alpha$, eventually leading to enhanced angiogenesis and increased tumour growth.

Retinoblastoma cells provide an ideal model to test this possibility as the $\mathrm{Rb}$ and p53 pathways are, respectively, dysfunctional and intact in these cells. ${ }^{33}$ To compare angiogenesis in the presence and absence of p53, we knocked down (KD) p53 in the human $\mathrm{Y}^{34}$ (Y79 short hairpin (sh)p53) and WERI ${ }^{35}$ (WERI shp53) retinoblastoma cell lines that harbour WT p53 (Figure 5a and Supplementary Figure 6A). These cells, and control KD cells (Y79 shMX, WERI shMX), were injected intravitreally into NMRI nu/nu mice and subsequently monitored for the presence of a white reflex behind the pupil, an indicator of tumour growth. a

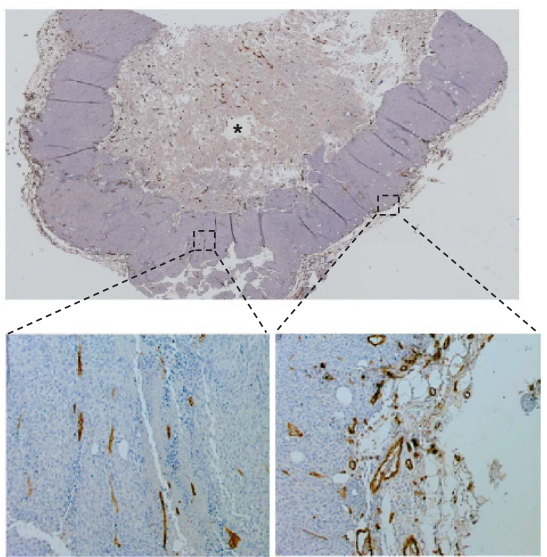

C

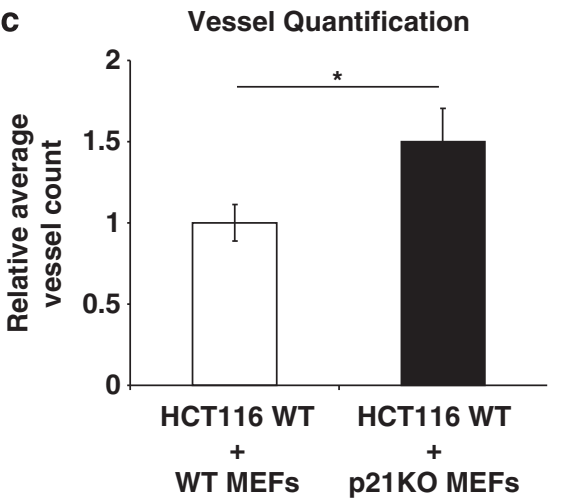

b

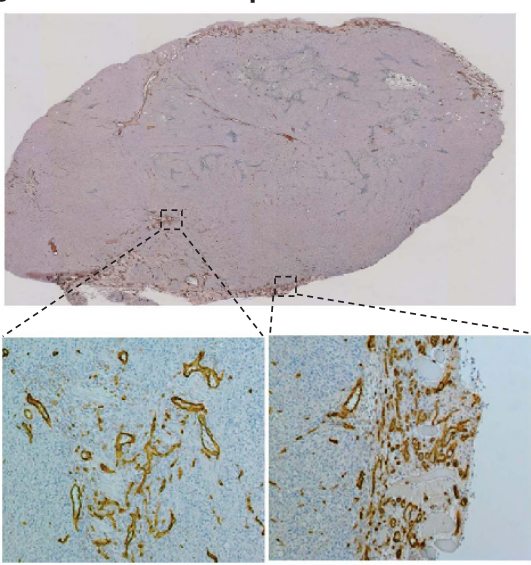

d

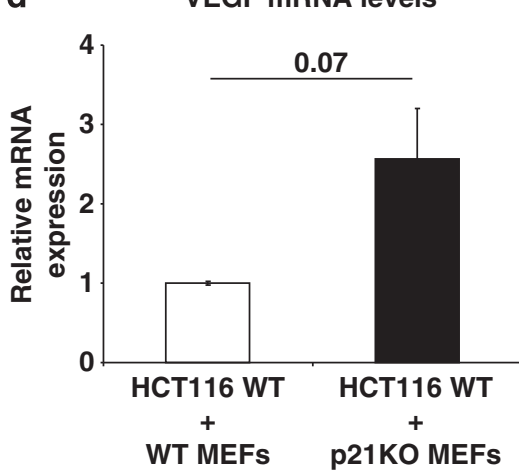

Figure 4 p21-null MEFs induce vascularization in xenotransplanted tumours. (a and b) Brightfield montaged $\times 40$ and $\times 100$ images of tumour sections stained with platelet endothelial cell adhesion molecule (PECAM). (a) HCT116 injected with WT MEFs. Most vessels surround the tumour tissue, with fewer vessels in the centre. Necrotic region is represented by asterisk. (b) HCT116 cells with p21 - / - MEFs. High density of vessels at the surrounding and the centre of the tissue. (c) Quantification of vessels using the Volocity software program. The tumours injected with p21 - I- MEFs $(n=18)$ on average contain more vessels than their WT counterparts ( $n=17) ; n$ represents the total number of slides for five and three tumours for p21 - I - and WT, respectively. (d) Relative VEGF mRNA levels measured by qRT-PCR ( $n=3$ ). Tumour samples with p21 - I - MEFs display more VEGF expression compared with their WT counterparts. Bars represent mean \pm S.E.M.; ${ }^{*} P \leqslant 0.05$ 
Tumours were collected 14 days after engraftment and stained for the endothelial marker CD31 as well as hypoxia. The Y79 and WERI shMX control eye tumours displayed more vessels than tumours arising from the $Y 79$ and WERI p53 KD cells (Figures $5 \mathrm{~b}$ and $\mathrm{c}$ and Supplementary Figures 5 and 6). These tumours were characterized by fewer necrotic regions and overall less hypoxia (Figures $5 b$ and $c$ and Supplementary Figures 5 and 6). Quantification of vessel densities for the Y79 tumours showed a highly significant $50 \%$ reduction $(P=0.001)$ in the p53 KD tumours (Figure $5 d$ ), which correlated with an approximate 1.5-fold decrease in VEGF levels (Figure 5e; $P=0.09$ ). These results provide in vivo evidence that $\mathrm{p} 53$ has a positive effect on tumour angiogenesis in Rb1-deficient tumours.

\section{Discussion}

Both p53 and VEGF have been shown to have essential roles in cancer formation. Previous conflicting results concerning the regulation of VEGF by $p 53$ can be attributed to the fact that previous experiments were performed on various tumour cell lines with different mutational profiles and response to hypoxia with respect to VEGF regulation. In addition, some of these in vitro studies were performed using transient expression assays that are sensitive to variations in experimental setup. $^{10,14}$ For this study, we used non-transformed primary MEFs from different genetic knockout backgrounds, which are more representative of physiological conditions. Using this approach, we have shown that p53 positively regulates VEGF expression during early stages of hypoxia and that $\mathrm{Rb} / \mathrm{p} 21$ acts indirectly to repress VEGF expression in primary nontransformed cells independently of effects on $\mathrm{Rb}$ phosphorylation.

Intriguingly, we found that p53-null cells showed a blunted VEGF mRNA response after $4 \mathrm{~h}$ of hypoxia. This does not contradict the fact that p53-null tumours are typically highly angiogenic. Overall, we observed increased levels of VEGF protein at $24 \mathrm{~h}$ of hypoxia in p53-null compared with WT cells (Supplementary Figure 1). It is important to note that although p53-null cells do not show initial induction, they also do not possess repressive activity on VEGF promoter activity, and therefore as long as the hypoxia state exists, there will be a

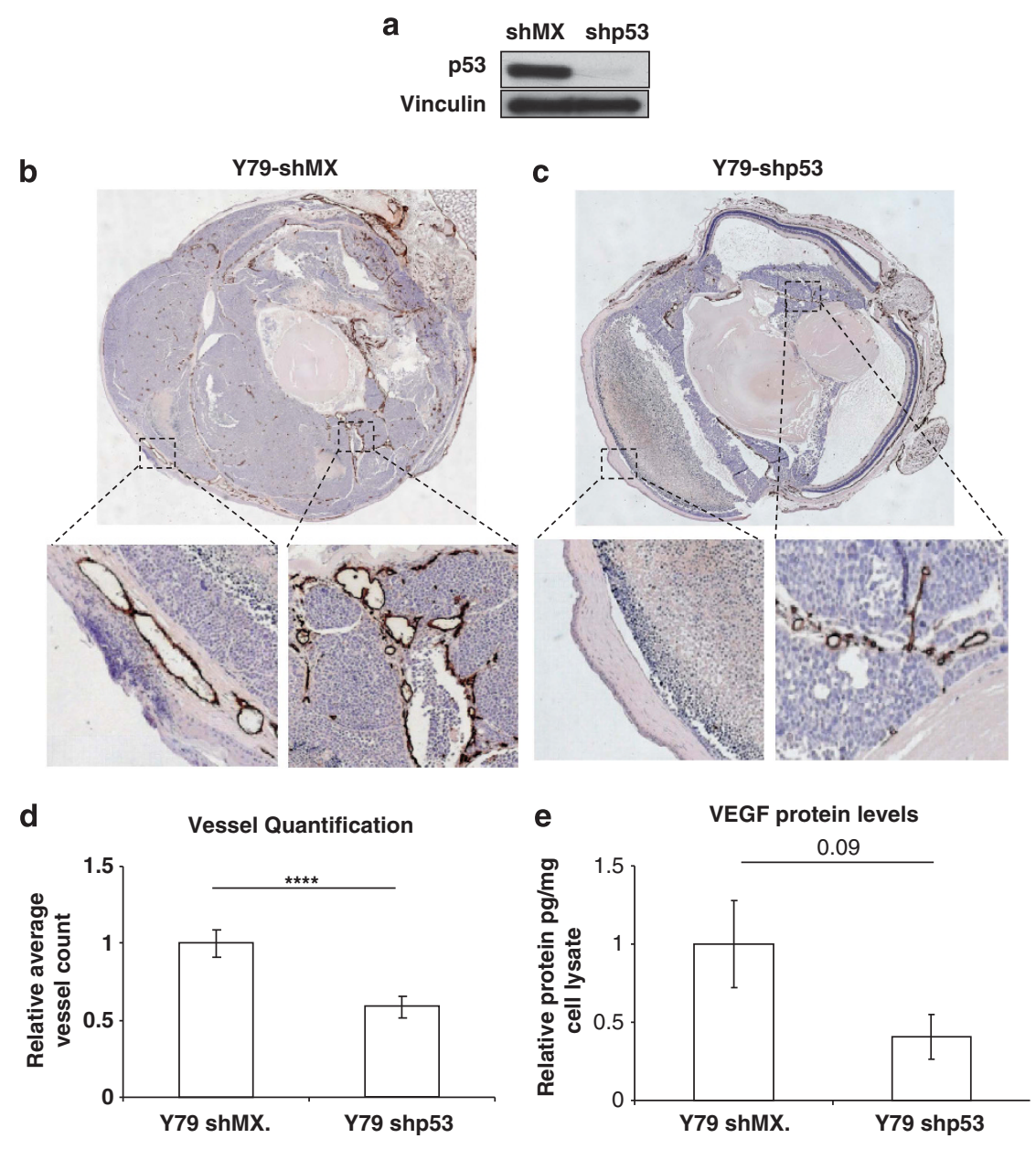

Figure 5 WT p53 promotes angiogenesis in retinoblastoma xenografts in the absence of an intact Rb pathway. (a) Western blot on Y79 cells showing knock down of p53 with short hairpin. (b and c) Brightfield montaged $\times 40$ images and computer-enlarged boxed regions of eye sections stained with PECAM. (b) Y79 shp53. (c) Y79 shMX. (d) Quantification of vessels using the Volocity software program. Y79 shp53 $(n=17)$ on average contain less vessels than Y79 shMX ( $n=15) ; n$ represents the total number of slides for six and seven tumours for Y79 shMX and Y79 shp53, respectively. (e) Relative picogram VEGF protein measured by enzyme-linked immunosorbent assay (ELISA) and normalized against a microgram of cell lysate $(n=3)$. Tumours with p53 short hairpin on average display less VEGF protein than their control counterparts. Bars represent mean \pm S.E.M.; ${ }^{* * *} P \leqslant 0.001$ 
constant steady state of VEGF mRNA production and accumulation that will be translated to increased VEGF protein. Here post-transcriptional/translational modifications that increase the stability of VEGF mRNA and protein during hypoxia should be taken into account. ${ }^{36}$

In this study, we have demonstrated that in the absence of $\mathrm{Rb} / \mathrm{p} 107$, VEGF levels are no longer repressed during prolonged hypoxia in primary MEFs. Second, we have demonstrated that p21-null MEFs also show a lack of repression of VEGF mRNA and protein under conditions of prolonged hypoxia, irrespective of the stabilization of p53. Under hypoxic conditions alone however, p53 and p21 protein levels are not changing and only upon DNA damage or Mdm2 inhibition are the protein levels of p53 and p21 increased. The lack of hypoxic induction of p53/p21 is consistent with previous reports; ${ }^{8,22}$ however, this lack of protein induction does not rule out changes in p53 transcriptional or p21 kinase activity towards their differential targets. Last, we have shown that E2F protein expression is lower during the initial phases of hypoxia than during prolonged hypoxia. This observation is consistent with the early induction and late repression of VEGF during hypoxia and with the findings by Qin and coworkers, ${ }^{13}$ who showed that E2F/p53 complex attenuates VEGF expression and that E2F-null mice display more angiogenesis compared with their WT counterparts. ${ }^{13}$

During normal cell-cycle regulation, cytotoxic stress induces p53 expression and stabilization, which in turn leads to increased p21 levels. p21 then represses the phosphorylation of $\mathrm{Rb}$ and decreases the amount of free $\mathrm{E} 2 \mathrm{~F}$ that can activate cell-cycle genes. However, under prolonged hypoxia p21 levels are not changing and the phosphorylation of Rb remains unchanged, yet there is apparently more E2F under extended hypoxic conditions to potentially act synergistically with p53 to repress VEGF. ${ }^{13}$ These data lead us to conclude therefore that the $\mathrm{p} 21 / \mathrm{E} 2 \mathrm{~F} / \mathrm{Rb}$ pathway acts as an indirect repressor of VEGF expression under conditions of continued hypoxia that are mechanistically distinct from the classical roles of the $\mathrm{p} 21 / \mathrm{E} 2 \mathrm{~F} / \mathrm{Rb}$ pathway in cell-cycle regulation.

Despite the lack of changes in its steady-state levels during extended hypoxia, our genetic deletion data clearly point to a role of p21 as an inhibitor of VEGF and the angiogenic programme. This is consistent with p21-null mice developing vascular tumours ${ }^{37}$ that may be related to increased VEGF levels. In keeping with this hypothesis, we have also demonstrated that when co-injected with human HCT116 cell line, p21null MEFs can drive an enhanced tumour angiogenic response that correlated with enhanced VEGF expression levels.

Our finding using retinoblastoma models where the continued presence of $p 53$ in the absence of a functional $R b$ pathway results in more vascularized tumours is novel and biologically relevant. It is known that retinoblastomas are highly angiogenic tumours and that vessel density correlates with both its invasiveness and metastatic potential. ${ }^{38,39}$ In case studies where patients with aggressive retinoblastoma failed to benefit from systemic chemotherapeutic treatment, biopsy samples showed upregulation of the VEGF pathway stressing the relevance of this pathway with poor prognosis. ${ }^{38}$ Our findings provide further insight into why these tumours are so highly angiogenic and caution against reactivation of p53 as the sole treatment in these $\mathrm{Rb}$-deficient tumours.
For instance, tumours treated with Nutlin-3 (Mdm2 antagonist), which would stabilize WT TP53, fail to regress and a reduction of tumour burden is only observed in combination with another drug (topotecan, a topoisomerase I inhibitor). ${ }^{33}$

In conclusion, the stress response protein p53 interacts synergistically with the physiological regulator $\mathrm{HIF}-1 \alpha^{40}$ to promote VEGF expression during acute hypoxia to adjust perturbations in oxygen and nutrient homoeostasis and indirectly regulates cellular metabolism. ${ }^{41}$ However, during prolonged hypoxic exposure, which is also observed in tumours, p53 acts as a repressor to prevent VEGF induction and inhibits angiogenesis in a p21/Rb-dependent manner. These findings have significant therapeutic implications for WT p53 tumours carrying a disrupted Rb/p21 pathway. Here, enhanced VEGF levels could fuel vessel abnormalization, ${ }^{4}$ increase tumour lymphatic metastatic potential ${ }^{42}$ and/or potentially increase cancer stem cell numbers in the tumour, ${ }^{7}$ thereby exacerbating tumour refractiveness to chemo- and radiation therapy. Thus, p53 stabilization therapies aimed at killing tumour cells should only be considered in the context of evidence of an intact p21/Rb pathway or should be combined with strategies that may normalize tumour vasculature that can act in synergy with stabilized p53 in enhancing tumour cell apoptosis.

\section{Materials and Methods}

Cell culture and conditions. MEFs were isolated from mouse embryos according to the protocol described in Migliorini et al. ${ }^{43}$ Human colorectal carcinoma cell line, HCT116, was kindly provided by Prof. B Vogelstein (Johns Hopkins University, Baltimore, MD, USA). MEFs and HCT116 cells were grown in DMEM supplemented with $10 \%$ FBS, $2 \mathrm{mM}$ L-glutamine, $0.1 \mathrm{mM}$ non-essential amino acids, $50 \mu \mathrm{M}$ $\beta$-mercaptoethanol, and $50 \mathrm{U} / \mathrm{ml}$ penicillin and streptomycin. Human retinoblastoma cell lines Y79 and WERI and clones with shp53 were grown in RPMl 1640 medium supplemented with $10 \% \mathrm{FBS}$, and $50 \mathrm{U} / \mathrm{ml}$ penicillin and streptomycin.

Hypoxia setting. MEFs at passage 2 (P2) were grown in normoxic condition $\left(20 \% \mathrm{O}_{2}, 5 \% \mathrm{CO}_{2}\right)$. At DO the cells are splitted (P3) and counted for a confluency of approximately $70 \%$ for the non-treated and hypoxia $4 \mathrm{~h}$ samples and $50 \%$ confluency for the hypoxia $24 \mathrm{~h}$ samples. At D1 the medium is refreshed and cells are placed in hypoxic chamber $\left(0.5 \% \mathrm{O}_{2}, 5 \% \mathrm{CO}_{2}\right)$. After $4 \mathrm{~h}$, the non-treated and hypoxia $4 \mathrm{~h}$ cells are harvested for RNA and protein, and the supernatant is collected for ELISA. The same procedure is also applied for the hypoxia $24 \mathrm{~h}$ samples.

Hypoxyprobe. To detect tumour tissue hypoxia mice are injected intraperitoneally with Hypoxyprobe-1 Kit (HPI Inc., Burlington, MA, USA) at a dosage of $60 \mathrm{mg} / \mathrm{kg}$ body weight at $90 \mathrm{~min}$ before being sacrificed. The tumours are then dissected and processed as explained in the histology section. For hypoxia detection on the paraffin-fixed tissues, Hypoxyprobe-1 Kit (HPI Inc.; no. HP1$100 \mathrm{Kit}$ ) was used according to the manufacturer's protocol.

Histology. Tumours were fixed overnight in $4 \%$ paraformaldehyde at $4{ }^{\circ} \mathrm{C}$, processed for paraffin embedding and sectioned at $5 \mu \mathrm{m}$. Sections were stained with haematoxylin and eosin. Immunohistochemistry was performed according to the protocol from Renaissance TSA Biotin System (NEL 700; Perkin-Elmer, Waltham, MA, USA), using rat-anti-mouse CD31 antibody (BD Biosciences, Erembodegem, Belgium; 1:50), followed by incubation with biotinylated anti-rat antibody (BD Biosciences).

Chromatin immunoprecipitation. ChIP assays were performed using protocol adapted from Ohkubo et al. ${ }^{44}$ Briefly, subconfluent $15 \mathrm{~cm}$ dishes were crosslinked in $1 \%$ formaldehyde for $10 \mathrm{~min}$ at room temperature. The reaction was stopped by the addition of glycine in PBS to a final concentration of $125 \mathrm{mM}$. Cells were transferred on ice, rinsed three times with ice-cold $1 \times \mathrm{PBS}$ and scraped in PBS with $1 \mathrm{mM}$ EDTA and protease inhibitors. Lysates were centrifuged for $10 \mathrm{~min}$ at $4{ }^{\circ} \mathrm{C}$ at 4000 r.p.m.; further cell pellets were resuspended in $1 \mathrm{ml} \mathrm{ChIP} \mathrm{lysis}$ buffer (0.1 M PIPES, $\mathrm{pH}=8,1 \mathrm{M} \mathrm{KCl}, 10 \% \mathrm{NP} 40)$ with protease inhibitor and $0.5 \mathrm{mM}$ PMSF, and centrifuged for additional $5 \mathrm{~min}$ at $4^{\circ} \mathrm{C}$ at 5000 r.p.m. Finally, 
pellets were resuspended in $1 \mathrm{ml}$ of sonication buffer $(1 \mathrm{M}$ Tris- $\mathrm{HCl}, \mathrm{pH}=8,0.5 \mathrm{M}$ EDTA, $20 \%$ SDS, $10 \%$ deoxycholic acid) with protease inhibitor, and subsequently sonicated at high power in a Bioruptor sonicator, Liège, Belgium (cycle of $3 \times 10 \mathrm{~min}$ sonication, $3 \times 10 \mathrm{~min}$ pause; interval $30 \mathrm{~s}$ ). Samples were centrifuged at $4{ }^{\circ} \mathrm{C}$, and the supernatants were transferred to a new tube. The DNA concentration was determined and aliquots of DNA were taken to represent input material. For $100 \mu \mathrm{g}$ of DNA chromatin solution, $3 \mu \mathrm{g}$ of anti-p53 antibody (mouse, clone 1C12; Cell Signalling Technology, Leiden, The Netherlands; no. 2524 lot 4) was used. IPs were performed for $2 \mathrm{~h}$ at $4{ }^{\circ} \mathrm{C}$ using $50 \%$ slurry of protein $\mathrm{G}$ beads with $0.1 \mu \mathrm{g} / \mu \mathrm{l} \mathrm{BSA}$, and $0.1 \mu \mathrm{g} / \mu \mathrm{l}$ salmon sperm. Beads were subsequently washed three times in wash buffer (10 mM HEPES, $\mathrm{pH}=7.6,0.5 \%$ Nonidet P-40, $1 \mathrm{mM}$ EDTA, $200 \mathrm{mM} \mathrm{NaCl}, 10 \%$ glycerol, supplemented with protease and phosphatase inhibitors). Elution of the crosslinked material was performed by incubating the beads, while rotating, for $20 \mathrm{~min}$ at room temperature in elution buffer ( $1 \% \mathrm{SDS}, 0.1 \mathrm{M} \mathrm{NaHCO}_{3}$ ). After centrifugation, the supernatant was transferred into a new tube. A measure of $16 \mu \mathrm{l}$ of $5 \mathrm{M} \mathrm{NaCl}$ was added to the samples and to the input chromatin $(50 \mu l+350 \mu$ l elution buffer). All the samples were de-crosslinked overnight at $65^{\circ} \mathrm{C}$. Chromatin DNA was purified using QIAquick PCR Purification Kit (Qiagen, Venlo, Netherlands; no. 28104), according to the manufacturer's protocol. Finally, both the input and co-precipitated DNA were analysed using real-time qPCR. The following genes were used as reference: $\beta$-actin, hydroxymethylbilane synthase (HMBS), glyceraldehyde-3phosphate dehydrogenase (Gapdh), VEGFR1, VEGF R2 and VEGF R3. Primers used to amplify the specific genomic regions are shown in Supplementary Table 1.

Lentivirus production, cell infection and selection. HEK293T cells were transfected by calcium phosphate for $6 \mathrm{~h}$ with a mix of vectors pSPAX2, pMD2G (Trono Lab, Lausanne, Switzerland), pDG2iV5puro encoding an $\mathrm{N}$ terminus $3 \times$ HA-tagged human p21. Multicistronic pDG2iV5puro is a modified version of the pLenti6 V5/DEST vector (Invitrogen, Life Technologies Europe B.V., Gent, Belgium). It contains an expression cassette under the control of a Tet-responsive element allowing the doxycycline-inducible expression of the gene of interest and an SV40 promoter controlling rtTA3 transactivator expression, followed by an IRES and a puromycin-resistance marker. Transfected HEK293T supernatant was collected after 2 days, clarified, filtered and concentrated on Amicon filter (Millipore, Overijse, Belgium). MEF p21-null cells were infected for $24 \mathrm{~h}$ by the addition in culture medium of a volume of lentiviruses corresponding to $100 \mu \mathrm{g}$ of p24 capsid protein per 50.103 cells (titrated by ELISA according to the manufacturer's protocol; INNOTEST HIV Antigen mAb; Innogenetics, Gent, Belgium). Infected cells were selected by antibiotic resistance with a final concentration of $1.5 \mu \mathrm{g} / \mathrm{ml}$ of puromycin (InvivoGen, Toulouse, France), $24 \mathrm{~h}$ before hypoxia experiments cells are treated with $1 \mu \mathrm{g} / \mathrm{ml}$ doxycycline to activate ectopic p21 expression.

Western blot. MEFs were dissolved in Giordano buffer $(50 \mathrm{mM}$ Tris- $\mathrm{HCl}, \mathrm{pH}$ $7.4,250 \mathrm{mM} \mathrm{NaCl}, 0.1 \%$ Triton X-100, $5 \mathrm{mM}$ EDTA) or $1 \times$ Laemmli buffer (10\% glycerol, $100 \mathrm{mM}$ DDT, $62.5 \mathrm{mM}$ Tris) containing phosphatase and protease inhibitors (Sigma-Aldrich BVBA, Diegem, Belgium). The protein concentration was determined by Bio-Rad DC Protein Assay (Bio-Rad Laboratories N.V., Nazareth Eke, Belgium; no. 500-0112) and $30 \mu \mathrm{g}$ of each sample was fractionated by SDSPAGE and transferred to a polyvinylidene difluoride (PVDF) membrane (Amersham Biosciences, GE Healthcare Europe Gmbh, Diegem, Belgium). The primary antibodies used were as follows: anti-p53 (mouse, clone 1C12, 1:1000; Cell Signalling Technology ; no. 2524 lot 4), anti-p21 (rabbit, clone C-19, 1:200; Santa Cruz, Biotechnology, Inc., Heidelberg, Germany; no. sc-397), anti- $\beta$-tubulin (rabbit, 1:1000; Abcam, Cambridge, UK; no. ab6064), anti-E2F1 (rabbit, clone c-20, 1: 250; Santa Cruz Biotechnology; no. sc-193), anti-phosphohistone H3 (Ser10) (rabbit, 1:200; Cell Signalling Technology; no. 9701), anti- $\alpha$-tubulin (mouse, clone DM1A, 1:1000; Santa Cruz Biotechnology; no. sc-32293), and anti-Rb (mouse, 1:500; BD Pharmingen, Erembodegem, Belgium; no. 554136), anti-phospho-Rb (pT826) (rabbit, 1:500; Biosource Invitrogen, Gent, Belgium; no. 44-576G) and Vinculin (human, clone hV1N-1, Diegem Belgium, 1: 1000; SigmaAldrich BVBA; no. V9131). WERI cells were lysed with Triton $1 \%$ lysis buffer (50 mM HEPES, pH =7.5, $150 \mathrm{mM} \mathrm{NaCl}, 1 \mathrm{mM}$ EDTA, $2.5 \mathrm{mM}$ EGTA) containing phosphatase and protease inhibitors (Sigma-Aldrich BVBA). Primary antibodies used were as follows: anti-p53 (mouse, clone DO-1, 1:1000; Santa Cruz Biotechnology; no. sc-126) and anti-GAPDH (mouse, clone 6C5, 1: 1000; Abcam; no. ab8245). The secondary antibodies used were either horseradish peroxidase (Amersham Biosciences) or IRDye 680 anti-mouse IgG (goat, 1:10 000; Li-Cor, Bad Homburg, Germany; no. 926-32220) and IRDye 800CW anti-rabbit IgG (goat,
1:10000; Li-Cor; no. 926-32211). For the detection, Li-Cor Odyssey infrared imaging system (Li-Cor) was used.

ELISA. Secreted VEGF was measures from the supernatant of cell cultures using Mouse VEGF Quantikine ELISA Kit (R\&D Systems Europe Ltd., Oxon, UK; no. MMV00) according to the manufacturer's instructions. Values were normalized against total protein concentration of cell lysates.

Microscopy and vessel quantification of tumours. For whole images of tumour and eye sections, AxioVision 4.8.2 (Carl Zeiss N.V., Zaventem, Belgium) was used. Tumours were isolated when they reached the size of $2 \mathrm{~cm}^{3}$. Sequential sectioning of paraffin-embedded tumours were performed for three WT and five p21-null samples or six Y79 shMX control eye tumours and seven of Y79 p53 mutant tumours. Vessel growth was analysed using CD31 immunoreactivity and quantificated using the Volocity software program (Perkin-Elmer).

Statistical analysis. All statistical claims are based on standard paired Student's $t$-test.

Xenotransplantation assay. All animal experiments were approved by the Ethical Committee for care and use of laboratory animals of the University of Ghent. HCT116 cells were injected with either p21-null or WT cells with a ratio of $3: 4$ subcutaneously in the flank of athymic nude (NMRI nu/nu) mice. For retinoblastoma model, 6000 cells of Y79/or WERI shMX as control (short hairpin against mouse $\mathrm{MdmX}$ in a human tumour cell line) and Y79/or WERI shp53 were injected intravitreally in the eyes of athymic nude (NMRI nu/nu) mice. For retinoblastoma model of WERI cells, the same procedure as Y79 cells was performed.

In vitro Cre excision. An HTNC-expressing Escherichia coli strain, created by Peitz et al., ${ }^{45}$ was used for the expression of the modified Cre recombinase, which was purified using an Ni-NTA resin column and concentrated by dialysis. For Cre-mediated deletion, MEF culture was treated with HTNC-containing MEF medium without FBS for $8 \mathrm{~h}$. Subsequently, cells were washed with $1 \times$ PBS and refreshed with the MEF medium.

Quantitative reverse transcription-polymerase chain reactions. Total RNA was isolated using RNeasy Plus Mini Kit (Qiagen). cDNA was synthesized using the First Strand cDNA Synthesis Kit (Roche Diagnostics Belgium, Vilvoorde, Belgium) with oligo(dT) primer by starting from equal amounts of RNA as measured by a NanoDrop spectrophotometer (Thermo Scientific, Doornveld, Belgium). qRT-PCRs were performed using the LightCycler 480 SYBR Green I Master (Roche) and monitored on a LightCycler 480 system (Roche). Gene expression was standardized against housekeeping genes $\beta$-actin, HMBS and Gapdh. All qRT-PCR primers that were used are listed in Supplementary Table 2.

Luciferase activity assay. Dr. Patricia D'Amore (Laboratory Schepens Eye Research Institute, Boston, MA, USA) kindly provided VEGF promoter luciferase construct. $^{26}$ MEFs were transfected with VEGF promoter luciferase construct and pUT651 (Eurogentec S.A., Seraing, Belgium) as control with 4:3 ratio, respectively. Non-treated samples were kept at $20 \% \mathrm{O}_{2}$ and others were exposed to hypoxia for $4 \mathrm{~h}$. Luciferase activity was measured using the Galactostar Kit (Tropix, Life Technologies Europe B.V.) according to the manufacturer's protocol.

Bioinformatic analysis. Putative transcription factor-binding sites in the VEGFA promoter and intron 1 region were identified using the web-based analysis tool ConTra (Broos et al., ${ }^{46}$ ). In a Multiz alignment of the promoter (2000 upstream) and first intronic region of VEGFA from different species, highly conserved binding sites were detected for $\mathrm{p} 53, \mathrm{HIF} 1-\alpha$. Sites were identified based on the position weight matrices from the JASPAR (Copenhagen University, Ole Maaloes Vej 5, Denmark) and TransFac (Wolfenbuettel, Germany); databases. The JASPAR matrices included MA0259.1 (HIF-1). From TransFac three matrices were used as follows: V\$P53_02 and V\$P53_DECAMER_Q2 (p53), and \$HIF1_Q3 (HIF-1 $\alpha)$. Three regions containing highly conserved p53binding motifs, of which two also included conserved HIF-1 sites, were experimentally validated: R1 in the promoter region on human chr6: 43736 903-43736999 and on mouse chr17: 46170 223-46170318 (Figure 2 and Supplementary Figure 2); R2 in intron 1 on human chr6: 4373926543739313 and on mouse chr17: 46167974-46168022 (Figure 2 and Supplementary Figure 2); and R3 in intron 1 on human chr6: $43740348-$ 43740405 and mouse chr17: 46166840-46166895 (Figure 2 and 
Supplementary Figure 2). Figures were generated with the program Jalview using the multifasta alignment and feature colour files produced by the ConTra tool. The regions were mapped onto the mouse genome $(\mathrm{mm} 9)$ in the UCSC genome browser to determine their exact position in the promoter and first intronic region of the VEGFA gene.

Acknowledgements. We thank Dr. Patricia D'Amore (Laboratory Schepens Eye Research Institute, Boston, MA, USA) for kindly providing the VEGF promoter luciferase construct. We also thank Dr. Stefan Vinckier from Leuven microscopy core and Dr. Christopher Guerin, Eef Parthoens and Amanda Goncalves from DMBR microscopy core for assistance in tumour vasculature quantification. We also wish to thank Jessika Wynendaele for the western blot on the WERI cells. MFG and DN funding was provided by the VIB International Ph.D. Programme. SG is a postdoctoral fellow of the Basic Science Research Foundation-Flanders (FWO). XB is supported by the Fondation Rose et Jean Hoguet and the Fonds David et Alice Van Buuren. PPR is a Senior Research Associate of the FRS-FNRS. MFG, JH, SG, $\mathrm{JCM}$, and PPR designed experiments and wrote the manuscript. MFG, SG, DN, XB, $\mathrm{AZ}, \mathrm{PH}, \mathrm{SB}, \mathrm{KH}, \mathrm{LH}$ and $\mathrm{BD}$ performed experiments.

1. Olsson AK, Dimberg A, Kreuger J, Claesson-Welsh L. VEGF receptor signalling - in control of vascular function. Nat Rev Mol Cell Biol 2006; 7: 359-371.

2. Moreira IS, Fernandes PA, Ramos MJ. Vascular endothelial growth factor (VEGF) inhibition - a critical review. Anticancer Agents Med Chem 2007; 7: 223-245.

3. Poon RT, Fan ST, Wong J. Clinical implications of circulating angiogenic factors in cancer patients. J Clin Oncol 2001; 19: 1207-1225.

4. Goel S, Duda DG, Xu L, Munn LL, Boucher Y, Fukumura D et al. Normalization of the vasculature for treatment of cancer and other diseases. Physiol Rev 2011; 91: 1071-1121.

5. Liu W, Xu J, Wang M, Wang Q, Bi Y, Han M. Tumor-derived vascular endothelial growth factor (VEGF) - a facilitates tumor metastasis through the VEGF-VEGFR1 signaling pathway. Int J Oncol 2011; 39: 1213-1220.

6. Loges S, Mazzone M, Hohensinner P. Carmeliet P. Silencing or fueling metastasis with VEGF inhibitors: antiangiogenesis revisited. Cancer Cell 2009; 15: 167-170.

7. Beck B, Driessens G, Goossens S, Youssef KK, Kuchnio A, Caauwe A et al. A vascular niche and a VEGF-Nrp1 loop regulate the initiation and stemness of skin tumours. Nature 2011; 478: 399-403.

8. Sermeus A, Michiels C. Reciprocal influence of the p53 and the hypoxic pathways. Cell Death Dis 2011; 2: e164.

9. Vousden KH, Lu X. Live or let die: the cell's response to p53. Nat Rev 2002; 2: 594-604

10. Agani F, Kirsch DG, Friedman SL, Kastan MB, Semenza GL. P53 does not repress hypoxia-induced transcription of the vascular endothelial growth factor gene. Cancer Res 1997; 57: 4474-4477.

11. Mukhopadhyay D, Tsiokas L, Sukhatme VP. Wild-type p53 and v-Src exert opposing influences on human vascular endothelial growth factor gene expression. Cancer Res 1995; 55: 6161-6165.

12. Pal S, Datta K, Mukhopadhyay D. Central role of $p 53$ on regulation of vascular permeability factor/vascular endothelial growth factor (VPF/NEGF) expression in mammary carcinoma. Cancer Res 2001; 61: 6952-6957.

13. Qin G, Kishore R, Dolan CM, Silver M, Wecker A, Luedemann CN et al. Cell cycle regulator E2F1 modulates angiogenesis via p53-dependent transcriptional control of VEGF. Proc Natl Acad Sci USA 2006; 103: 11015-11020.

14. Zhang L, Yu D, Hu M, Xiong S, Lang A, Ellis LM et al. Wild-type p53 suppresses angiogenesis in human leiomyosarcoma and synovial sarcoma by transcriptional suppression of vascula endothelial growth factor expression. Cancer Res 2000; 60: 3655-3661.

15. Carroll VA, Ashcroft M. Role of hypoxia-inducible factor (HIF)-1alpha versus HIF-2alpha in the regulation of HIF target genes in response to hypoxia, insulin-like growth factor-l, or loss of von Hippel-Lindau function: implications for targeting the HIF pathway. Cancer Res 2006: 66: 6264-6270.

16. An WGKM, Simon MC, Maltepe E, Blagosklonny MV, Neckers LM. Stabilization of wildtype p53 by hypoxia-inducible factor 1alpha. Nature 1998; 392: 405-408.

17. Chen D, Li M, Luo J, Gu W. Direct interactions between HIF-1 alpha and Mdm2 modulate p53 function. J Biol Chem 2003; 278: 13595-13598.

18. Ravi R, Mookerjee B, Bhujwalla ZM, Sutter $\mathrm{CH}$, Artemov D, Zeng $\mathrm{Q}$ et al. Regulation of tumor angiogenesis by p53-induced degradation of hypoxia-inducible factor 1alpha. Genes Dev 2000; 14: 34-44.

19. Nieminen AL, Qanungo S, Schneider EA, Jiang BH, Agani FH. Mdm2 and HIF-1alpha interaction in tumor cells during hypoxia. J Cell Physiol 2005; 204: 364-369.

20. Fukasawa M, Tsuchiya T, Takayama E, Shinomiya N, Uyeda K, Sakakibara R et al. Identification and characterization of the hypoxia-responsive element of the human placental 6-phosphofructo-2-kinase/fructose-2 6-bisphosphatase gene. J Biochem 2004; 136: 273-277.

21. Kurz EU, Douglas P, Lees-Miller SP. Doxorubicin activates ATM-dependent phosphorylation of multiple downstream targets in part through the generation of reactive oxygen species. J Biol Chem 2004; 279: 53272-53281.

22. Graeber TGPJ, Tsai M, Monica K, Fornace AJ, Giaccia AJ. Hypoxia induces accumulation of p53 protein, but activation of a G1-phase checkpoint by low-oxygen conditions is independent of p53 status. Mol Cell Biol 1994; 14: 6264-6277.

23. Francoz S, Froment P, Bogaerts S, De Clercq S, Maetens M, Doumont G et al. Mdm4 and Mdm2 cooperate to inhibit p53 activity in proliferating and quiescent cells in vivo. Proc Natl Acad Sci USA 2006; 103: 3232-3237.

24. Hooghe B, Hulpiau P, van Roy F, De Bleser P. ConTra: a promoter alignment analysis tool for identification of transcription factor binding sites across species. Nucleic Acids Res 2008; 36: W128-W132.

25. Forsythe JA, Jiang BH, lyer NV, Agani F, Leung SW, Koos RD et al. Activation of vascular endothelial growth factor gene transcription by hypoxia-inducible factor 1. Mol Cell Biol 1996; 16: 4604-4613.

26. Yamakuchi M, Lotterman CD, Bao C, Hruban RH, Karim B, Mendell JT et al. P53-induced microRNA-107 inhibits HIF-1 and tumor angiogenesis. Proc Natl Acad Sci USA 2010; 107: 6334-6339.

27. Dimri GP, Nakanishi M, Desprez PY, Smith JR, Campisi J. Inhibition of E2F activity by the cyclin-dependent protein kinase inhibitor p21 in cells expressing or lacking a functional retinoblastoma protein. Mol Cell Biol 1996; 16: 2987-2997.

28. Gurley LR, D'Anna JA, Barham SS, Deaven LL, Tobey RA. Histone phosphorylation and chromatin structure during mitosis in Chinese hamster cells. Eur J Biochem 1978; 84: $1-15$

29. Nowak SJ, Corces VG. Phosphorylation of histone H3: a balancing act between chromosome condensation and transcriptional activation. Trends Genet 2004; 20: 214-220.

30. Erez N, Truitt M, Olson P, Arron ST, Hanahan D. Cancer-associated fibroblasts are activated in incipient neoplasia to orchestrate tumor-promoting inflammation in an NF-kappaB-dependent manner. Cancer Cell 2010; 17: 135-147.

31. Hanahan D, Coussens LM. Accessories to the crime: functions of cells recruited to the tumor microenvironment. Cancer Cell 2012; 21: 309-322.

32. Schroy PC 3rd, Brown-Shimer S, Kim K, Johnson KA, Murnane MJ, Yang S et al. Detection of p21ras mutations in colorectal adenomas and carcinomas by enzyme-linked immunosorbent assay. Cancer 1995; 76: 201-209.

33. Laurie NA, Donovan SL, Shih CS, Zhang J, Mills N, Fuller C et al. Inactivation of the p53 pathway in retinoblastoma. Nature 2006; 444: 61-66.

34. Green AL Meek ES, White DW Stevens RH, Ackerman LD, Judisch GF et al Retinoblastoma Y79 cell line: a study of membrane structures. Albrecht Von Graefes Arch Klin Exp Ophthalmol 1979; 211: 279-287.

35. Campbell M, Chader GJ. Retinoblastoma cells in tissue culture. Ophthalmic Paediatr Genet 1988; 9: 171-199.

36. Pereira ER, Liao N, Neale GA, Hendershot LM. Transcriptional and post-transcriptional regulation of proangiogenic factors by the unfolded protein response. PLoS One 2010; 5 , pii $\mathrm{e} 12521$.

37. Martin-Caballero J, Flores JM, Garcia-Palencia P. Serrano M. Tumor susceptibility of p21(Waf1/Cip1)-deficient mice. Cancer Res 2001; 61: 6234-6238.

38. Fortunato P, Pillozzi S, Tamburini A, Pollazzi L, Franchi A, La Torre A et al. Irresponsiveness of two retinoblastoma cases to conservative therapy correlates with up-regulation of hERG1 channels and of the VEGF-A pathway. BMC Cancer 2010; 10: 504.

39. Yang H, Cheng R, Liu G, Zhong Q, Li C, Cai W et al. PEDF inhibits growth of retinoblastoma by anti-angiogenic activity. Cancer Sci 2009; 100: 2419-2425.

40. Maxwell PH. Hypoxia-inducible factor as a physiological regulator. Exp Physiol 2005; 90: 791-797.

41. Maddocks OD, Vousden KH. Metabolic regulation by p53. J Mol Med (Berl) 2011; 89: 237-245.

42. Hirakawa S, Kodama S, Kunstfeld R, Kajiya K, Brown LF, Detmar M. VEGF-A induces tumor and sentinel lymph node lymphangiogenesis and promotes lymphatic metastasis. $J$ Exp Med 2005; 201: 1089-1099.

43. Migliorini D, Lazzerini Denchi E, Danovi D, Jochemsen A, Capillo M, Gobbi A et al. Mdm4 (Mdmx) regulates $\mathrm{p} 53$-induced growth arrest and neuronal cell death during early embryonic mouse development. Mol Cell Biol 2002; 22: 5527-5538.

44. Ohkubo S, Tanaka T, Taya Y, Kitazato K, Prives C. Excess HDM2 impacts cell cycle and apoptosis and has a selective effect on p53-dependent transcription. J Biol Chem 2006; 281: 16943-16950.

45. Peitz M, Pfannkuche K, Rajewsky K, Edenhofer F. Ability of the hydrophobic FGF and basic TAT peptides to promote cellular uptake of recombinant Cre recombinase: a tool for efficient genetic engineering of mammalian genomes. Proc Natl Acad Sci USA 2002; 99: 4489-4494.

46. Broos S, Hulpiau P, Galle J, Hooghe B, Van Roy F, De Bleser P. ConTra v2: a tool to identify transcription factor binding sites across species, update 2011.. Nucleic Acids Res 2011; 39: W74-78 